\title{
UMA ANÁLISE ECONÔMICA DA SOCIALIDADE NOS CONTRATOS PRIVADOS RELACIONAIS
}

\author{
http://dx.doi.org/10.21527/2176-6622.2019.52.251-266
}

Recebido em: 8/3/2019

Modificações requeridas em: 8/6/2019

Aceito em: 21/6/2019

\section{Sandro Crispim Gonçalves Nóbrega Magalhães}

Especialista em Direito Civil e Empresarial pela Universidade Federal de Pernambuco. Bacharel em Direito pelo Centro Universitário de João Pessoa. http://lattes.cnpq.br/0083040071262177. https://orcid.org/0000-0001-9975-9356. sandrocgnm@gmail.com

\section{Humberto João Carneiro Filho}

Doutor e mestre em Direito pela Universidade Federal de Pernambuco. Professor da Faculdade de Direito do Recife (Ufpe). Advogado. http://lattes.cnpq.br/3384917281390006. http://orcid.org/0000-0003-3810-9522.

\section{RESUMO}

O presente artigo visa a explicar a importância de estimular uma socialidade nos contratos relacionais, tomando por base a Análise Econômica do Direito (AED). Apesar de atribuir-se a Richard Posner a divulgação da AED, percebe-se que foi com Ronald Coase, em 1960, quando da publicação de The problem of the social cost, que o tema ganhou mais relevância, principalmente pela aferição da geração recíproca de efeitos prejudiciais próprios da exploração das atividades produtivas. Nesse sentido, deve-se buscar a diminuição dos custos transacionais endógenos e valorizar a autocomposição e decisões legislativas e/ou judiciais aptas a produzir mais-valia e, consequentemente, desenvolvimento sustentável. Para compreender a temática posta, é necessário analisar sistemáticas negociais clássica, neoclássica e de longa duração e algumas das espécies contratuais, bem como ponderar sobre entropias negociais e gestão de risco. Para tanto, utiliza-se uma abordagem exploratória por meio do método dedutivo, tudo por intermédio de uma pesquisa qualitativa bibliográfica e videográfica.

Palavras-chave: AED. Socialidade. Contrato relacional. Mais-valia. Desenvolvimento.

\section{AN ECONOMIC ANALYSIS OF SOCIALITY IN RELATIONAL PRIVATE CONTRACTS}

\section{ABSTRACT}

This article aims to explain the importance to encourage the sociality in a kind of long term contracts, based on the Economic Analysis of Law - LAE. Although Richard Posner was credited as the author of the LAE, it earned more relevance in 1960, as of the publication of The problem of the social cost, that was written by Ronald Coase, that examined the reciprocal harmful effects that happens by the exploitation of productive activities. In this view, is necessary to look to mitigate endogenous transactional costs, to promote self-composition and legislative and/ or judicial decisions able to foment surplus value and, consequently, sustainable development. To understand the current theme, we must study classical, neoclassical and long term contractual systems, some species of contracts, as well as the business entropies and the manegement of risks. For that, an exploratory approach is used, through deductive method, all per a qualitative bibliographical and videographical research.

Keywords: LAE. Sociality. Relational contract. Surplus value. Development.

\section{SUMÁRIO}

1 Introdução. 2 A socialidade em The Problem of Social Cost de Ronald Coase. 3 Distinção entre Contratos Tipo, de Adesão e Relacionais. 3.1 Contratualização Clássica, Neoclássica e Relacional. 3.2 Espécies Contratuais Tipo, de Adesão e Relacional. 3.3 Estandardização dos Instrumentos Contratuais. 4 Análise Econômica nos Contratos Privados Relacionais: Entropias e Gestão de Riscos nas Incompletudes. 5 Conclusão. 6 Referências. 


\section{INTRODUÇÃO}

A (re)interpretação da Ciência Jurídica sob uma ótica integralizada, visualizada, mais proeminentemente, em Ronald Dworkin, possibilitou significados inúmeros ao texto legal (FERNANDES, 2014, p. 194-198). Inspirado também nesse padrão ideológico (conjugado com o do realismo), desenvolveu-se a Análise Econômica do Direito - AED - de Richard Posner (Law and economics - LAE, Law and development; ou, ainda, Law and Finance), que consiste em um enfoque ${ }^{1}$ jurídico voltado ao legislador e ao aplicador do Direito. ${ }^{2}$

Encontram-se normas de teor jus-econômico quando da interpenetração nos cânones da eticidade, socialidade e operabilidade, no tocante aos direitos de propriedade, posse (e.g. as usucapiões dos §§3으 e 4으, artigo 1.228 , do $\mathrm{CC} / 02$ ), contratos, responsabilidade, etc. ${ }^{3}$

A deixar de lado, por aspectos didáticos, a importância da AED em outros institutos não exatamente cíveis contratuais (usucapião sui generis, ${ }^{4}$ contribuição de melhoria, princípios ambientais, defesa da concorrência, judicialização da saúde pública, desapropriação por zona, créditos de carbono, seguridade social, perda do tempo produtivo, intervenção direta do Estado na economia, Teoria do Desestímulo, etc.), o presente artigo busca preparar, galgado em uma metoditização econômica, o exame dos aspectos relacionados à utilidade, mais-valia social, ou seja, ao valor excedente (surplus value ${ }^{5}$ ) nos contratos relacionais, e pontuar também sobre uma gestão jurídica de riscos negociais com base, inclusive, na funcionalização das estruturas jurídicas.

Segundo Maria Paula Reis Vaz Freire (2015), as concepções econômicas do Direito têm escopo na eficiência e na justiça social e na diminuição de custos de transação, ao reconhecer que o valor de um bem se diferencia do de toda a operação. Assim, na AED aproveita-se, mais adequadamente, as liberdades volitivas (autonomias da vontade e privada) por meio da ponderação de ideias quantitativas e qualitativas referentes a dados econômicos, culturais e sociais, bem como alusivos aos comportamentos estratégicos dos agentes negociais (e de terceiros). É o Direito a estabelecer diálogo com a microeconomia (PORTO, 2013, passim). ${ }^{6}$

Nesse sentido, para o presente trabalho a AED, per si, não aborda a predileção por sistemas econômicos capitalistas ou planificados, ${ }^{7}$ sendo desaconselhável se imiscuir em estultificantes ortodoxias postas aprioristicamente, mantendo-se certa objetividade na pesquisa jurídica, apesar do tônus crítico-material que envolve a temática.

Amartya Sen (2009, p. 55) explicou a relevância mercadológica do aproveitamento das oportunidades por meio das comodidades dispostas aos sujeitos, cujos intitulamentos econômicos vão se constituir (ou serem desconstituídos) com supedâneo nas características do desenvolvimento econômico, conjugado às liberdades.

\footnotetext{
Sobre tal natureza jurídica, Cf. VANOSSI, 2008, p. 90.

2 Merece nota esclarecer que "Coase did pioneering work on the ways in which transaction costs and property rights affect business and society. In his most influential paper, 'The Problem of Social Cost' (1960), he developed what later became known as the Coase theorem, arguing that when information and transaction costs are low, the market will produce an efficient solution to the problem of nuisances without regard to where the law places the liability for the nuisance. (ENCYCLOPAEDIA BRITANNICA, 2018).

3 Como exemplo dessa interpenetração, no que se refere ao direito de propriedade, tem-se a delimitação da necessidade de escrituração pública como essencial, via de regra, à validade dos negócios jurídicos sobre direitos reais, a demonstrar a opção legislativa por segurança jurídica por meio da publicização de negócios privados imobiliários; é o que se depreende do teor do art. 108 do Código Civil, que lança uma gestão "ex ante" de riscos negociais. Sem embargo, ainda, ao conteúdo que se extrai dos artigos 187 c/c o 422 , do respectivo diploma normativo, a possibilitar, dentro de um mesmo fato jurídico, a aferição de responsabilidades contratuais e aquilianas.

4 Parte da doutrina dá outra nomenclatura e natureza jurídica - a de desapropriação judicial -, cf. Tartuce (2013, p. 129-160) e, ainda, Castilho (2010, p. 136-137). Cf. Biazus (2008), também, para uma explicação sobre a adoção de uma das respectivas terminologias.

5 O termo surplus value refere-se ao valor total do contrato, a não considerar, tão somente, a operação principal e seu objeto, mas, sim, o custo global da operação econômica, ou seja, dispêndios transacionais, logísticos, de completude negocial, etc. Para uma mais profícua compreensão, ver Loyola (2009, passim).

6 Sobre o diálogo entre o Direito e a Economia: "Há, pois, entre a Economia e o Direito uma interação (sic.) constante, não se podendo afirmar que a primeira cause o segundo, ou que o Direito seja mera 'roupagem ideológica' de uma dada forma de produção. Há, em suma, uma interação dialética entre o econômico e o jurídico, não sendo possível reduzir essa relação a nexos causais, nem tampouco a uma relação entre forma e conteúdo" (REALE, 2007, p. 21).

7 Para desmitificar conceitos superficiais acerca de planificação econômica, tem-se que: "Firms are like centrally planned economies, he wrote, but unlike the latter they are formed because of people's voluntary choices. But why do people make these choices? The answer, wrote Coase, is 'marketing costs.'." LYBRARY ECONOMICS LIBERTY, 2018.
} 
O Código Civil de 2002, ao delimitar a socialidade da propriedade, do contrato e das regras de responsabilidade cível, trouxe - por intermédio não só de cláusulas gerais e preceitos indeterminados -, balizas economicistas que, até pouco, não eram assim propagadas, como os artigos 187, 258, 413, 421, 478, 479, 480, 715, 1.130, bem como os $\S \S 1$ 으 ao 40 do artigo 1.228 , todos do Código Civil, dentre outros regramentos. ${ }^{8}$ É, pois, oportuno ver (e interpretar) o Direito Civil também sob termos econômicos, a fim de garantir sustentabilidade aos contratos relacionais.

No campo contratual, âmago do presente escólio, a AED revela-se peremptória para explorar o binômio benefícios marginais versus custos marginais, bem como quanto às entropias negociais, que se dão em razão de vicissitudes relacionadas a oportunismos, ativos específicos e assimetrias informacionais. Isso, sem embargo à afirmação, enfrentada por Viviane Taís Azoia e Marcia Carla Ribeiro (2016, p. 5), do contrato como meio equitativo de distribuição de direitos.

Marcelo Bertoldi e Marcia Carla Ribeiro (2008, p. 729) arrematam que a prática empresarial está afeta à tônica contratual, que lhe regula os atos desde alguns aspectos inerentes aos fatores de produção (capital, mão de obra, tecnologia e matéria-prima) à abertura de uma conta bancária. É ela, a prática empresarial, que, v.g., é impactada pela incidência de contratos relacionais, sendo a franchisage um exemplo sobre tal afirmação.

Sobre a consubstanciação do Direito Empresarial, também âmbito de interesse da AED, é pertinente explicar que a unificação formal do Direito Privado, angariada no CC/02 (Lei 10.406/02) e tentada no Projeto Inglês de Souza (em 1911), não o extinguiu, mantendo suas autonomias didática e substancial, ressalvada uma concepção absoluta do sistema jurídico. Tal raciocínio é extensível ao campo contratual (BERTOLDI; RIBEIRO, 2008, p. 38-40, 730). ${ }^{9}$

É necessário traçar os assuntos a serem aclarados, a fim de se garantir uma compreensão das soluções técnicas que serão difundidas adiante. Em linhas gerais, tem-se os seguintes tópicos: socialidade economicista e desenvolvimento; distinção entre contratos-tipo, de adesão, relacionais e estandardizados; e, finalmente, a análise econômica dos negócios relacionais.

Enfim, a escolha de tais pontos faz-se necessária para construir uma cadeia lógica de raciocínio a partir da explicação dos institutos gerais que circunscrevem a matéria até adentrar na questão das externalidades e gestão negocial de riscos.

Ocorre que o universo econômico passou a também ser visto como ínsito ao paradigma da socialidade, porquanto é capaz de gerar mais intitulamentos a partir do crescimento de riquezas e sua melhor alocação. Nessa senda, observa-se a crescente relevância do contrato como instituto de circulação de bens, direitos e deveres, sendo preciso perlustrar acerca de algumas de suas espécies e sistemáticas, para, assim, então, entendê-lo sob um viés economicista.

\footnotetext{
${ }^{3}$ Os referidos artigos da codificação civil, em rol meramente elucidativo, dizem respeito, respectivamente, aos seguintes tópicos: abuso de direito; indivisibilidade obrigacional com causa econômica; redução da cláusula penal; resolução por onerosidade excessiva; modificação e preservação contratual; paradigma da função socioeconômica do contrato; indenizabilidade por perda da viabilidade econômica do contrato de agência/distribuição; recusa governamental de autorização à sociedade desprovida de função socioeconômica; função socioeconômica da propriedade, desapropriação e usucapião sui generis.

9 "A relação do Direito Comercial com o Direito Civil é tão intensa que, como se viu, várias foram as tentativas de uma unificação. Hoje existe um relacionamento bastante próximo no que diz respeito às obrigações e contratos civil e mercantis, tenho que ambos se abeberaram em uma mesma teoria geral" (BERTOLDI; RIBEIRO, 2008, p. 42).
} 


\section{A SOCIALIDADE EM "THE PROBLEM OF SOCIAL COST"DE RONALD COASE}

Embora a Análise Econômica do Direito - AED - ${ }^{10}$ tenha atraído mais relevância jurídica a partir dos estudos de Richard Posner, é, anteriormente, em Ronald Coase (1960), que o tema passa a fomentar certo interesse geral nos acadêmicos e aplicadores do Direito, especialmente em 1960, a partir de The problem of social cost, artigo publicado no The Jornal of Law and Economics, da Universidade de Chicago - Estados Unidos da América - EUA. ${ }^{11}$

É, contudo, com supedâneo nas relativas reflexões de Coase que buscamos abordar a AED, bem como quais os valores que lhe são insertos. Para tanto, é necessário frisar que as distinções básicas existentes entre o common e o civil law não são suficientes para atravancar o estudo da AED nos países de tradição romano-germânica, seja porque caminhou-se para uma interpenetração entre os dois ou, ainda, por causa da necessidade de se avaliar a propícia conveniência de regulação estatal. ${ }^{12}$

Percebe-se, desde logo, o quanto a questão da socialidade ${ }^{13}$ é fundamental para uma profícua compreensão da temática. Ao adentrar-se no custo social das escolhas - das transações entre os sujeitos do Direito -, tem-se fim na geração de desenvolvimento socioeconômico, sem relegar, todavia, a análise fundada na pessoa humana, até mesmo porque os direitos fundamentais estão, hoje, e cada vez mais, imersos na preocupação sobre qual amanhã construiremos à(s) posteridade(s)..$^{14} \mathrm{O}$ recrudescimento de uma perspectiva mais individualizadora não pode, precipuamente nesse contexto, desprezar a importância de eventual dirigismo.

Em The problem of social cost, como típico do direito consuetudinário, faz-se um acurado estudo sobre alguns dos ditos restatements of the Law; isso a partir do exame de casos julgados na Inglaterra e nos EUA. Exemplo é a doctrine of the lost grant (COASE, 1960, p. 14), que poderia levar-nos não ao direito de usucapir (pois seria descomedido confundir a aquisição da propriedade com o alcance de um, ou de alguns, de seus poderes residuais), mas, por que não dizer, à surrectio (e, consequentemente, à supressio), figuras parcelares da boa-fé objetiva. ${ }^{15}$

Embora os precedentes trabalhados por Coase $^{16}$ sejam mais alusivos ao tema da responsabilidade civil aquiliana, em razão das externalidades, percebe-se não se poder enjeitar as repercussões emanadas sobre os direitos de propriedade e sobre o campo contratual. ${ }^{17}$

Além disso, é necessário afastar panoramas meramente monoculares, e, nesses termos, as externalidades negativas, a priori, seriam recíprocas, pois à medida que efeitos prejudiciais são lançados sobre determinado sujeito, este, ao tentar valer-se de alguma pretensão para conter o que lhe é deletério, também aflige a outrem (COASE, 1960, p. 2).

10 "De acordo com a Análise Econômica do Direito (AED), a economia, especialmente a microeconomia, deve ser utilizada para resolver problemas legais, e, por outro lado, o Direito acaba por influenciar a Economia" (OLIVEIRA, 2014. p. 31).

${ }^{11}$ Apenas para sublinhar, foi afirmado, em trabalho publicado com Renata Menezes e Bianca Magalhães (MENEZES; MAGALHÃES; MAGALHÃES, 2018, p. 1434), que o tema jus econômico já foi considerado desde Joseph Schumpeter (GICO JUNIOR, 2010) ou, ainda, desde o próprio Adam Smith (VELOSO, 2013, p. 113).

12 Uma abordagem instrutiva pode ser encontrada em brevíssimo ensaio publicado por Nuno Garoupa (2018), da Faculdade de Direito da Universidade de Illinois.

13 "Quanto à alegação de que o princípio da 'socialidade' acaba gerando a massificação e sacrificando a individualidade, componente essencial de um Código Civil, trata-se de tolice tão evidente que não merece nem comporta discussão" (REALE, 1998).

${ }^{14}$ Trata-se do princípio da equidade intergeracional, que, "em última análise, assegura igualdade entre as gerações em sua relação com o sistema natural. Não há prioridade da geração presente em relação às futuras, que também necessitam ver assegurado um piso vital mínimo" (MARCHESAN; STEIGLEDER; CAPELLI, 2013, p. 68).

15 Sobre as figuras parcelares da boa-fé, ver Penteado (2006).

${ }^{16}$ Alguns dos leading cases trabalhados no referido texto são: Sturges v. Bridgman; Cooke v. Forbes; Bryant v. Lefever; Bass v. Gregory; Webb $v$. Bird; Rex v. Ronkett; Attorney General v. Doughty; Adams v. Ursell; Andreae v. Selfridge and Company Ltda.; Delta Air Corporation v. Kersey; Kersey v. City of Atlanta; Thrasher v. City of Atlanta; Georgia Railroad and Banking Co. v. Maddox; Smith v. New England Aircraft Co.; Bland $v$. Yates.

${ }^{17}$ No campo da responsabilidade civil, segundo os ditames da AED, é pertinente analisar as regras de responsabilização civil subjetiva e objetiva, compliance, precaução, informação, nível de atividade, fator de aversão ao risco e custos de administração (BATTESINI, 2015). 
A qualificação negativa ou positiva das externalidades, logo, somente pode ser otimizada sob um prisma social de custos versus benefícios, a ser solucionada por intermédio da autocomposição das partes, a partir das transações peculiares de mercado, ou, ainda, por meio da regulação estatal (government regulations), seja sob uma abordagem positiva ou normativa. ${ }^{18}$

Em todo caso, devem ser avaliados os custos de produção, negociação, renegociação, litigância e de ordenação econômica. A atuação estatal, segundo Maria Luiza Feitosa (2005, p. 70), representa um dos ditos mecanismos regulatórios heterônomos.

Para mais, com base na interpretação dos estudos de Pigou (COASE, 1960, passim), amplamente debatidos por Coase, tem-se defendido uma inafastável compensação dos impactos prejudiciais; no entanto tal solução não se justifica quando o custo da contrapartida gera mais malefícios do que benefícios, a exigir, dessarte, a aferição do valor social (ou desvalor) do resultado, denominados, por Coase (1960, passim), de services ou disservices.

No campo do direito de propriedade, por exemplo, maximizando a socialidade, afirma-se que a propriedade imobiliária não é ilimitada, salvo se puder ser removida de um lugar para o outro (hipótese em que deixaria de ser imóvel, a não ser que por ficção jurídica, mesmo que ope legis). É incontestável conceber tal raciocínio, seja porque nos apresenta efetiva retórica atestar que a função social não limita o direito de propriedade (a compô-lo), seja pela cogência do direito de passagem, da possibilidade de ingerência em razão do dano infecto, etc. ${ }^{19}$

A esse respeito, se o direito de propriedade, como dito, é limitado, não se pode falar em direito absoluto a fazer com que alguém deixe, por exemplo, de poluir. Tal raciocínio, aliás, revela-se importante ao Direito Empresarial, basta que se aperceba os fatores de produção como "prerrogativas" (direitos) autônomas. ${ }^{20}$

Quanto aos contratos, âmbito de nosso atual e mais específico interesse, Coase $(1960$, p. 8) já o introduz, mesmo que implicitamente, como uma das vias antecedentes ao reconhecimento da responsabilidade civil, isto porque é fator considerável (embora não seja o único) ao incremento das transações de mercado, tão imprescindíveis à expansão da eficiência ${ }^{21}$, que é - uma das, senão - a pedra de toque da AED.

É nessa linha que Fernando Araújo (2007, p. 18), da Faculdade de Direito da Universidade de Lisboa, afirma: "o contrato é essencialmente um facilitador da circulação de titularidades de valores e de modos de governo conjunto (ou governação) de problemas atinentes ao conhecimento, ao poder e aos interesses".

Ocorre que as negociações e/ou renegociações contratuais, mediante uma prognose dos efeitos nocivos, pode diminuir muitos dos custos de transação e afastar a responsabilidade cível por meio, e.g., do pagamento prévio (e consensual) de compensações por externalidades, e melhor atender os ditames dos custos sociais de produção, isso porque é capaz de gerar (mais das vezes, porém não sempre) desenvolvimento sustentável, a mitigar, por exemplo, elevadas despesas de litigância e/ou regulação estatal. ${ }^{22}$

\footnotetext{
${ }^{18}$ Acerca de tais abordagens, ver Ribeiro; Campos (2012, p. 314).

19 Para ler a asserção original: "The rights of a land-owner are not unlimited. It is not even always possible for him to remove the land to another place, for instance, by quarrying it. And although it may be possible for him to exclude some people from using "his" land, this may not be true of others. For example, some people may have the right to cross the land. Furthermore, it may or may not be possible to erect certain types of buildings or to grow certain crops or to use particular drainage systems on the land. This does not come about simply because of Government regulation. It would be equally true under the common law. In fact it would be true under any system of law. A system in which the rights of individuals were unlimited would be one in which there were no rights to acquire" (COASE, 1960, p. 44).

${ }^{20} \mathrm{Veja}$, "if factors of production are thought of as rights, it becomes easier to understand that the right to do something which has a harmful effect (such as the creation of smoke, noise, smells, etc.) is also a factor of production. Just as we may use a piece of land in such a way as to prevent someone else from crossing it, or parking his car, or building his house upon it, so we may use it in such a way as to deny him a view or quiet or unpolluted air. The cost of exercising a right (of using a factor of production) is always the loss which is suffered elsewhere in consequence of the exercise of that right-the inability to cross land, to park a car, to build a house, to enjoy a view, to have peace and quiet or to breathe clean air" (Ibid.).

21 "No campo do direito privado, três noções se tornam particularmente recorrentes: eficiência, falhas de mercado e monopólios. Articuladas em duas antigas sedes (o direito dos contratos e o direito societário, já identificado com o direito empresarial) e no âmbito de uma disciplina nascente (o direito antitruste), essas noções marcaram os primeiros passos de um movimento que, a partir de Chicago (e em seguida de New Haven), passou a ser chamado de Análise Econômica do Direito" (SILVA FILHO, 2014, p. 125).

${ }^{22}$ Coase (1960, p. 16) pontua in verbis: "In these conditions the initial delimitation of legal rights does have an effect on the efficiency with which the economic system operates. One arrangement of rights may bring about a greater value of production than any other."
} 
É interessante, ainda nessa linha, notar que Coase (1960, p. 16) atribui ao contrato, notadamente ao societário (ou ao estabelecimento dos peculiares esquemas societários), uma lógica galgada na diminuição dos custos produtivos (e maximização da eficiência), uma vez, pois, indene de dúvidas, que a natureza jurídica do contrato está imersa no domínio da valoração econômica. Nesse contexto, dada a complexidade das relações mercadológicas, expõe-se sobre a natureza contratual relacional. ${ }^{23}$

\section{DISTINÇÃO ENTRE CONTRATOS TIPO, DE ADESÃO E RELACIONAIS}

\subsection{Contratualização Clássica, Neoclássica e Relacional}

Para Feitosa (2005, p. 62), os contratos são estruturados (e reestruturados) em conformidade com os esquemas clássicos, ${ }^{24}$ neoclássicos ${ }^{25}$ e relacionais, e aí não se pode menoscabar o que de bom cada modelo trouxe ao Direito.

Nota-se que o entendimento sobre tais concepções é dado a partir da apreensão de uma maior ou menor emancipação das partes quanto à fixação das cláusulas contratuais, ou seja, por meio da análise da intervenção estatal nas liberdades volitivas.

No pensamento dito "clássico", parte-se do enaltecimento (hiperbólico) das liberdades, a não se admitir a exagerada atuação do poder público no direito privado, no sentido de refrear as prerrogativas dispostas aos sujeitos da relação contratual.

Sem embargo, errônea é a crítica que se faz ao "classicismo" iluminista quando da suposta ausência de alguma regulação estatal sobre os contratos, pois afronta-se, assim, a consubstanciação do próprio positivismo jurídico, a inviabilizar, por exemplo, a delimitação de uma teoria geral (dos contratos) em plano legislativo. Tal raciocínio, conclui-se, seria mais condizente com o direito consuetudinário embora nem a ele se aplique perfeitamente, tendo em vista a delimitação de restatements of the Law of contracts, a partir da construção de decisões paradigmáticas de observância obrigatória.

O que há no período clássico, notadamente do século 19, é o superdimensionamento dos valores privados, ${ }^{26}$ a desamarrar supostas mordaças públicas, próprias ainda de uma tradição feudal, do pertencimento medieval, embora o conceito de público - como o conhecemos hoje - seja deveras incipiente em tal período, mediante consolidação de institutos jurídicos abalizadores de liberdades particulares desvigiadas. Nesse sentido,

A busca implacável de que o indivíduo, com sua vontade e seus direitos subjetivos, deveria ser posto acima da coletividade e do interesse comum, estava alicerçada, regra geral, pela grande maioria dos Estados e seus respectivos ordenamentos jurídicos e econômicos, assim, a tendência era de uma grande disparidade social e uma segregação econômica. Neste vagar, os sistemas legislativos casuísticos ganharam relevo com a presunção do legislador em regulamentar toda e qualquer situação da sociedade, engessando, por vezes, o Poder Judiciário e a atividade dos magistrados, buscando a tão aclamada segurança jurídica e o dogma do pacta sunt servanda como standart do direito romano e das codificações subsequentes (SCRAMIN NETO; FERREIRA, 2013, p. 56).

\footnotetext{
${ }_{23}$ "But where contracts are peculiarly difficult to draw up and an attempt to describe what the parties have agreed to do or not to do (e.g. the amount and kind of a smell or noise that they may make or will not make) would necessitate a lengthy and highly involved document, and, where, as is probable, a long-term contract would be desirable..." (Ibid.).

24 "O período clássico, marcado pela idéia de sistematização das regras jurídicas e pelo surgimento no campo jus-positivo do constitucionalismo e das codificações civis (com destaque para o Code Napoléon de 1804 e para o código civil alemão de 1896, o célebre BGB - Bürgerliches Gesetzbuch), é representativo dessa atitude genérica de precaução contra as possibilidades de danos que viessem a ocorrer no curso da execução contratual" (FEITOSA, 2005, p. 68)

25 "No entanto, a partir de meados do século passado, as necessidades de racionalização, planejamento, rapidez e eficácia dos negócios conduziram à sistematização de uma prática contratual padronizada, estandardizada, capaz de se ajustar à produção e à distribuição também standards" (Ibid., p. 69).

${ }^{26}$ Em modernidade líquida (BAUMAN, 2001, passim) vê-se a questão pública voltar a ser trespassada por questões privadas, tal fenomenologia não é somente concernente aos aspectos mais íntimos da pessoa humana (aí sim uma novidade da época atual e vindoura), mas, também, e muito, em detrimento da cultura de consumo.
} 
À vista disso, a majoração das liberdades subjetivas (de contratar e de eleger o objeto do contrato - autonomias da vontade e privada) não deve ser caracterizada só por uma letargia estatal, até pela proscrição a uma proteção insuficiente quanto aos aspectos positivos da atuação pública, no sentido de uma inteligência que vai além do (apenas) abstencionismo, (que foi) tão espargido em relação aos direitos civis e políticos. Tem-se, então, que o projeto clássico é "assinalado pelo voluntarismo e pelo respeito quase incondicional aos postulados da autonomia da vontade e da liberdade de contratar" (FEITOSA, 2005, p. 62).

No que concerne à concepção neoclássica, parte-se de uma evidenciação das intervenções estatais como consubstanciantes da segurança jurídica, no sentido de valer-se de uma função social dos contratos com lastro na contenção da ruptura dos sinalagmas contratuais, que ocorrem a partir da exploração indevida da posição dominante, tudo isso como corolário, por exemplo, de oportunismos na fixação de contratos de adesão com cláusulas abusivas. É o estado como regulador privado (FEITOSA, 2005, p. 70).

No neoclassicismo há uma influição das ideias oriundas do estado social de direito(s) (comunitarista), no afã de uma maior planificação normativa. Se, por um lado, essa "metodologia" abalizou o avanço que representa o paradigma da socialidade, por outro minorou as liberdades econômicas e, embora represente avanço, é insuficiente, ainda, a uma acurada concepção de desenvolvimento sustentável, a engessar, não poucas vezes, os agentes de mercado, isto é, as relações privadas mercadológicas, quando da débil percepção dos vetores econômicos.

É, todavia, importante ressaltar que essa socialidade é encetada como uma reação aos desmandos da quadra liberal, a partir dos estropícios do industrialismo, que, inclusive, culminaram na bestialidade em que mergulhou o mundo em meados do século $20 .{ }^{27}$

Nesse meio tempo, os imperativos neoclássicos legitimaram-se na massificação das relações contratuais, também advindas das rápidas transformações comerciais que exigiram a formulação de contratos com cláusulas uniformes a fim de melhor urdir a prestação de serviços básicos e financeiros à população, contratos cativos (ASSIS NETO; DE JESUS; DE MELO, 2013, p. 912-916).

Por fim, engendrada em detrimento da velocidade da economia global, que permitiu, ante o fenômeno de globalização (social, econômica, cultural e jurídica), uma percepção do contrato como "disciplinador mas também como produtor do risco" (FEITOSA, 2005, p. 64), emerge uma concepção relacional de contratos, que se perfaz ante a necessidade de constante rediscussão das cláusulas contratuais dispostas e predispostas, isso no intuito de aprimorar a gestão de riscos inerentes à contratação. ${ }^{28}$

Sobre a álea, fala-se de uma nova tipologia de riscos, a definir, em linhas gerais, ameaças de crédito, de mercado, jurídico-legais, operacionais, técnicas e globais (FEITOSA, 2005, p. 64-67). Não é objetivo do presente artigo, entretanto, abordar, detalhadamente, tais fenomenologias, mas, sim a(s), metamorfose(s) que gera(ram) na teoria dos contratos.

Essa lógica de riscos está espargida na concepção das sociedades empresariais, pois contratos societários são, por essência, relacionais, inclusive quando se aquiesce que a empresa é uma planificação econômica simplificadora das relações mercadológicas (COASE, 1960, p. 16). Vejamos pois:

A empresa é essencialmente uma atividade de risco econômico. Embora seja desnecessário descer a maiores explicações sobre esta afirmação, dada sua notória comprovação, ela é importante, pois é a partir deste postulado fático e jurídico que se pode construir o raciocínio a ser exposto. $O$ risco de insucesso inerente à empresa

\footnotetext{
27 "A valente defesa da comunidade e a tentativa de restaurar sua posição negada pelos liberais dificilmente teriam acontecido se não fosse pelo fato de que os arreios com os quais a coletividade ata seus membros a uma história conjunta, ao costume, linguagem e escola, ficam cada vez mais esgarçados a cada ano que se passa" (BAUMAN, 2001, p. 194).

28 "A presente conjuntura, marcada, por um lado, pelo ressurgimento de elementos importantes do subjetivismo contratual e, por outro lado, pela reação institucional tendente à preservação dos motivos que autorizam o procedimento interventivo externo (objetivação contratual) em setores específicos da contratação, permite que se vislumbre no interior do enquadramento discursivo algumas circunstâncias reveladoras do panorama atual dos acordos. Nesse sentido, interessa-nos destacar, para além da relativização do elemento voluntário e intencional da declaração, as formas renovadas de produção de risco e os novos modos de gestão dos riscos engendrados no curso da relação contratual. É, portanto, nos limites da ambivalência acima encetada que se volta a pôr em relevo a ideia de risco, em perspectiva paradigmática, algo diversa da relação que sempre existiu entre o instituto do contrato e as situações que potencializam o prejuízo" (FEITOSA, 2005, p. 63).
} 
significa, patrimonialmente falando, a obrigação de que o agente econômico dedicado a esta atividade - o empresário - responda, com seu patrimônio, pelas obrigações assumidas em função e em decorrência deste exercício (PIMENTA, 2015, p. 329).

Eduardo Goulart Pimenta (2015, p. 330), em termos congruentes, afirma que "a pessoa jurídica no direito empresarial é hoje, antes de qualquer coisa, um elemento de limitação do risco econômico inerente à empresa." Nesses termos, é preciso perceber que os contratos empresariais, desde a fase pré-negocial, já estão imersos na preocupação dos riscos, tanto o é que se parte para uma escolha de modalidade societária também sobre uma ótica de distribuição de responsabilidade civil.

\subsection{Espécies Contratuais Tipo, de Adesão e Relacional}

Segundo Feitosa (2005, p. 71), embora exista certa semelhança, os ditos contratos relacionais (pactos de longa duração ou contratos relacionais de duração) não se confundem com ajustes de trato sucessivo ou de prestação continuada.

Os contratos de longa duração estão ligados a pormenores de forte teor economicista e, também, de cunho negocial dinâmico, dado que, além de serem mais das vezes plurilaterais, formam um processo aberto às constantes renegociações, isso ante a sempre contumaz premência de diminuição de custos transacionais. ${ }^{29} \mathrm{~A}$ jurista afirma que:

Nos contratos relacionais, projeta-se uma lógica diferente, determinada em regra pela análise econômica, pelo contingenciamento e pela flexibilidade, formando um continuum processual em cujo interior as partes (em geral, empresas comerciais) são instigadas à renegociação do acordo, ajustado e reajustado regularmente segundo as exigências internas, surgidas do processo econômico, de modo a não comprometer o funcionamento geral da rede de contratos (network contratual) que os agentes são levados a estruturar (FEITOSA, 2005, p. 71).

A afastar-se um tanto da sistemática neoclássica, os contratos relacionais potencializam a vontade das partes, salutar à mitigação dos riscos negociais e de renegociações.

Há, neles, uma prioridade na delimitação de cláusulas convencionais (no direito feito pelas partes), e aplaca-se, nesse prisma, a preponderância das regulações governamentais (apesar da crescente demanda regulatória) e o papel do juiz, ambos, instrumentos ditos inadequados à otimização da compreensão do surplus value negocial, mesmo quando se debate, v.g., onerosidade excessiva superveniente. É que, para a mais-valia, os contratantes devem tentar antever os custos, ou seja, as externalidades.

Nos contratos relacionais,,$^{30}$ salvo em um contexto indesejável, no qual estão presentes diversas entropias, exige-se, desde logo, a igualdade de poderes interpartes (equivalência material), a não se conceber polos hipossuficientes e/ou vulneráveis, mas sim paritários. ${ }^{31}$

À distinção do que ocorre nos instrumentos elaborados para adesão, ${ }^{32}$ não se difunde a estruturação de um padrão preconcebido (precedência e generalidade), como um formulário, posto que as transações mercadológicas exigem a discussão paritária de cada ponto contratual (e não unilateral), a tentar, inclusive, predizer as imprevisibilidades e as respectivas formas de reajuste e/ou revisão. A ótica dos contratos de longa duração está, pois, marcada pelo entendimento do negócio como um processo dinâmico, protraído.

\footnotetext{
${ }^{29}$ A questão dos custos de transação é, diga-se, uma evolução dos pensamentos de Coase por intermédio das consolidações advindas de Oliver Williamson, a partir do que seria economicismo institucional (nova economia institucional -- NEI). Sobre o assunto ver Zanella et al. $(2015$, p. 69 et seq).

30 "Os contratos relacionais ocorrem preferencialmente nos pactos plurilaterais e se assemelham, em geral, aos tipos societários, como as parcerias profissionais, os acordos empresariais de cooperação tecnológica, a formação de redes produtivas e de fornecimento de produtos, as franquias ou ainda os contratos de trabalho" (FEITOSA, 2005, p. 71).

${ }^{31}$ Cf. ASSIS NETO; DE JESUS; DE MELO, 2013, p. 911.

32 "Ao contrário do contrato de comum acordo (contrat de gré a gré) em que as partes negociam cláusula a cláusula, contrato de adesão é aquele cujas cláusulas são aprovadas por autoridade competente (cláusulas gerais para o fornecimento de água, energia elétrica, etc.), não podendo o consumidor recusá-las; ou estabelecidas pelo fornecedor de modo que o consumidor não possa discuti-las ou modificá-las substancialmente, cabendo-lhe somente o poder de aderir ou não ao contrato como um todo. São características dos contratos de adesão: serem previamente elaborados unilateralmente, serem ofertados uniformemente e em caráter geral e terem como modo de aceitação a simples adesão do aderente, vinculando-o à vontade do ofertante" (GARCIA, 2013, p. 437-438).
} 
Registre-se, mais uma vez, posto ser oportuno, que as lógicas contratuais clássica, neoclássica e relacional não se substituem entre si, como se não houvesse o que ser aproveitado em cada um desses esquemas; tem-se, portanto, uma reformulação de conceitos negociais (similar ao que sucede no estudo das dimensões de direitos fundamentais). Nessa linha, tem-se que:

Em cada período histórico (mesmo antes do advento do Estado Moderno) podem ser identificadas disposições prévias, de natureza legal, doutrinária e jurisprudencial, que acautelam o risco e procuram consubstanciar os elementos de certeza e de segurança dos negócios jurídicos (FEITOSA, 2005, p. 5).

Dessa forma, é equivocado pensar que - sob a égide dos instrumentos convencionais de longa duração - não existe regulação pública; ela subsiste, mas, dados alguns fatores, principalmente de ordem socioeconômica, permite-se a relativização e, consequentemente, a construção de novos arranjos.

Feitas tais considerações, define-se, por último, o contrato-tipo ${ }^{33}$ como aquele que não está voltado a um grupo indeterminado de aderentes, a destinar-se, por outro lado, a alguns agentes e/ou grupos econômicos, que, todavia, não se sobrepõem um ao outro, a existir equiparação material entre os sujeitos contratuais (VENOSA, 2006, p. 382). ${ }^{34}$

Nos contratos-tipo há paridade entre os sujeitos da relação negocial, mesmo que "pertencentes a categorias contrapostas e organizadas de interessados" (DIAS, 2009, p. 227), todavia, para a melhor adequação dos fatores de produção, é necessário padronizar as cláusulas abalizadoras das trocas mercantis, a fim de ensejar maior eficiência econômica. ${ }^{35}$

\subsection{Estandardização dos Instrumentos Contratuais}

A estandardização contratual é marca do neoclassicismo, estudada, mais detidamente, a partir da objetivação das relações contratuais, galgadas, principalmente, na massificação das relações consumeristas, dentro de uma ótica contratualista por adesão, de prestação sucessiva de comodidades públicas - v.g. água, energia e telefonia - conjuntamente com as práticas do mercado financeiro, em que o Estado, mas não somente ele, funciona como regulador privado, quando do disciplinamento exterior da vontade (FEITOSA, 2005, passim).

Nessa linha de raciocínio, os incoterms também estariam relacionados como standards de comércio exterior, entretanto são mais respeitantes aos contratos-tipo, visto serem voltados a grupos econômicos ligados à logística, exportação e/ou importação, e não ao mercado geral de consumo. Nos contratos-tipo, como visto, não é o órgão governamental que minora a liberdade negocial formal, mas as próprias práticas mercantis, por intermédio de seus agentes de transformação. Lê-se in verbis: ${ }^{36} 37$

É no âmbito do Direito Internacional que se tem notícias do histórico do contrato-tipo. Consta que, por conta do crescente volume e complexidade do comércio internacional, foi tomando corpo uma demanda premente por uma uniformização das estruturas e institutos que serviam de base legal para os negócios (DIAS, 2009, p. 229).

\footnotetext{
33 “..., foi no âmbito das associações de comerciantes, como a London Corn Trade Association, no século 19, que os primeiros contrato-tipo foram formalmente delineados. Os próprios comerciantes, através dessas suas associações de classe, tomaram a iniciativa de estabelecer certos padrões de conduta a serem observados por eles todos na condução das suas atividades empresariais" (DIAS, 2009, p. 229).

${ }^{34}$ Interessante ler texto bastante didático acerca das distinções entre os contratos tipos e de adesão. Para tanto, ver Teixeira (2011, p. 1-5).

35 "Existem alguns contratos nos quais, muito embora contenham cláusulas predefinidas, os contratantes se encontram em condições de igualdade e tiveram a oportunidade de discutir tais cláusulas; ou seja, as cláusulas predispostas são fruto de um mútuo consentimento dos contratantes, que se situam em de pé de igualdade (sic.). Trata-se do chamado contrato-tipo, geralmente utilizado entre os empresários para regular seu relacionamento" (BERTOLDI; RIBEIRO, 2008, p. 733).

${ }^{36}$ Não se pode, todavia, confundir os pactos estandardizados com algumas sistemáticas regulatórias internacionais, que, entende-se, são mais próprias a uma metodotização classicista, pois a normatização não se voltaria, em si, para o recrudescer de práticas socioeconômicas relativas aos direitos fundamentais de segunda dimensão, porém, muito mais, referentes às próprias liberdades de contratar, de circulação global de mercadorias e inovação. Dessa forma, tem-se: construção de elementos de conexão (do direito internacional privado), regras do GATT, Gats, Trips, Trims, SPS, TBT. Sobre esses tópicos, ver Portela (2015, passim).

${ }^{37}$ Os contratos internacionais (e as suas peculiaridades) são temas enfrentados por Nadia de Araújo (2011, p. 383-427), com destaque ao debate que se instalou acerca da possibilidade de as partes internacionais adotarem a cláusula de eleição de foro.
} 
Os contratos estandardizados nascem como uma contenção às liberdades volitivas (oportunistas); não obstante, não se pode negar que têm fulcro também em valores mercadológicos, fazendo com o que Estado (e/ou os representantes de grupos econômicos) incentive a atividade econômica, propondo padrões contratuais que afastam os custos ex ante de negociação, a residir, nesse ponto, uma afirmação com norte na socialidade economicista.

Ocorre que, com o avanço das relações econômicas e as novas modais de gestão de risco, percebeu-se que a padronização contratual não era capaz de afastar as intempéries de mercado e nem as ameaças operacionais, máxime quando sob uma perspectiva global (riscos da produção e de mercado pós-industrializado), de acentuada matriz econômico-financeira, a fazer, assim, necessário flexibilizar as molduras estatais postas, no intuito de zelar pela viabilidade socioeconômica dos negócios entabulados (FEITOSA, 2005, p. 3-4)

Para além disso, é pertinente questionar se a estandardização é hábil para mitigar custos de judicialização, ou se é mais adequada uma flexibilização que permita renegociações (com fixação de cláusulas de hardship, ${ }^{38}$ compromisso arbitral ou cláusula compromissória) e, assim, a preservação do contrato.

Some-se, ainda, o entendimento segundo o qual a formulação de padrões formais de contratos é (ou não) apta a tolher o próprio mercado concorrencial, a gerar, inclusive, tabelamento de preços (de juros, etc.). $\mathrm{O}$ assunto requer, pois, toda cautela.

É, entrementes, nessa toada que, para determinados aspectos do universo jurídico privado, começa a se falar em contratos relacionais de longa duração e de acordos incompletos, que, se ressalve, para fins de complementaridade, sob a égide do paradigma da eticidade, é temática abordada por Giuliana Bonanno Shunck (2013) e, também, por Tiago Faganello (2017).

\section{ANÁLISE ECONÔMICA NOS CONTRATOS PRIVADOS RELACIONAIS: Entropias e Gestão de Riscos nas Incompletudes}

A princípio, é necessário aclarar que Direito e Economia são ciências distintas, e não se deve, portanto, abandonar a perspectiva de complementaridade da AED, que é um enfoque jurídico ${ }^{39}$ (tendência, movimento), ${ }^{40}$ cuja realização empírica tende por flexibilizar a rigidez positivista por meio de uma cosmovisão (principalmente) microeconômica, dentro das perspectivas descritiva (efeitos), prescritiva (propositura de soluções) e consequencialista (sob o bem-estar social, socialidade) (FREIRE, 2015).

Dessa forma, sem se ater aos meandros das críticas feitas à AED, ressalte-se, de logo, não se adotar a negação da autonomia científica do Direito - aliás, sequer a AED o faz -, visto necessitar ser pensada (e repensada) quando da conjugação dos estudos e opiniões que lhe são ínsitas.

A AED, enfoque permeado pelos incentivos e penalizações à(s) (in)eficiência(s), galgada nos princípios da maximização das riquezas, do equilíbrio e da equidade, no paradigma do cálculo racional - mediante uma racionalidade econômica crítica à linguagem jurídica meramente tecnocrata -, não é apenas útil aos mercados explícitos, mas, também, aos comportamentos alheios ao mercado (ALVAREZ, 2006, passim).

\footnotetext{
38 "Cláusulas de hardship (ou cláusulas de adaptação), entendidas como aquelas que estabelecem um dever de renegociar o contrato, diante de determinadas circunstâncias e dificuldades (hardship)" (FEITOSA, 2005, p. 11).

${ }^{39}$ Sobre o tema: "Parece difícil imaginar que el 'enfoque' del análisis económico del Derecho (Law and Economic) pueda erigirse en una 'teoría general del Derecho y del Estado', en sustitución de las ya conocidas y que encuentran su base no en un mero plexo jurídico de andamiaje de una realidad concreta y circunscripta sino en una amplia y generalizada cosmovisión que marca la impronta de una era de la Historia: la del Estado de Derecho, constitucional y democrático. (...). Asimismo, la ventana o apertura hacia la 'consecuencialidad' (o 'consecuencialismo') como dato primordial de los resultados que persigue el análisis económico, es desde la misma manera un elemento no descartable ni olvidable en otros tipos de análisis, como el análisis político, sociológico, psicológico, moral, cultural, etc., de las más variadas manifestaciones de la vida comunitaria, en el plano nacional y universal" (VANOSSI, 2008, p. 90).

${ }^{40}$ Cf. AlVAREZ, 2006, p. 49.
} 
A AED, vista, e.g., a partir do "ótimo de Pareto" ${ }^{41}$ e dos "imperativos categóricos kantianos", com realce à ética, dentre outros caixilhos, não despreza a construção da dignidade da pessoa humana, e/ou dos direitos de personalidade, em seus aspectos histórico-culturais; isso, inclusive, porque a razão economicista está alinhada com o atendimento das necessidades humanas (ALVAREZ, 2006, passim).

Plausíveis sob o aspecto da identificação do indivíduo como o fim principal do Direito e, até mesmo, para que não se abandone os axiomas próprios do universo jurídico. As críticas que se fazem à AED, vista em seu todo, não merecem prosperar, pois nelas há um certo desprezo ao melhor entendimento hermenêutico normativo, que prepondera que o intérprete (se democrático) utilize todas as ferramentas e métodos de que dispõe.

Além disso, a temática não deve ser contaminada por preconceitos ideológicos, colocados a priori por qualquer intérprete, porque o impacto econômico do Direito existe, seja nas economias mais liberais ou nas planificadas, principalmente quando da aceitação de um viés economicista aplicável aos comportamentos alheios ao mercado.

Nesse sentido, entende-se perfeitamente cabível a AED não só aos sistemas jurídicos liberais puros (clássicos ocidentais), porém, inclusive, aos intervencionistas. Basta dizer que as ações estatais, quando o poder público é o monopolizador dos fatores de produção, também repercutem na economia, a se buscar aí, salvo sob preconcepções abrutalhadas (a serem desestimuladas em qualquer parte), eficiência socioeconômica e desenvolvimento sustentável.

No mais, a questão aqui enfrentada é, por um todo, de elevada importância para, dentro da seara da teoria dos contratos relacionais, se compreender como desenvolvem-se os ajustes e reajustes negociais, isso a partir da compreensão de externalidades que ocorrem de forma ex ante e/ou ex post, seja, com efeito, por seleção adversa e/ou riscos morais (FREIRE, 2015).

A AED, por fim, é uma reação à suposta negação do Direito em relação aos fatos sociais, a valorizar, assim, o pragmatismo jurídico como uma resposta ao convencionalismo e tradicionalismo, seja ele político, filosófico e/ou econômico, a recrudescer, até mesmo, a reaproximação das ciências jurídico-sociais com as ditas exatas (ALVAREZ, 2006, p. 50).

Maria Paula Reis Vaz Freire, da Faculdade de Direito da Universidade de Lisboa (2015), em palestra proferida junto ao Tribunal Regional Federal da 4a Região brasileira, ao esclarecer a AED como uma suposta recuperação da perspectiva individual das liberdades (sem desprezo à socialidade) e ao falar de uma realidade endógena das regras da arquitetura econômica, delineadas a partir das eficiência e equidade (como vetores de desenvolvimento), examina os problemas ligados às entropias contratuais.

Nesse sentido, a constatação de vicissitudes negociais pode gerar renegociações, sem, necessariamente, o uso dos mecanismos jurídico-formais, porquanto também delineáveis pelos usos do comércio ou pelos usos dos tráfegos. De mais a mais, a elaboração do instrumento contratual, suas renegociações e até a interpretação judicial ou extrajudicial (autocomposição), devem ser pautadas não sobre panoramas somente individuais, mas com base no paradigma da socialidade economicista (dirigismo contratual e funcionalização das estruturas jurídicas), ${ }^{42}$ ou seja, com supedâneo em desígnios coletivistas e/ou solidários, produtores de utilidade nos planos macrossocial e microssocial, a gerar surplus value e bem-estar. ${ }^{43}$ Ela destaca o oportunismo, as assimetrias informacionais ${ }^{44}$ e o uso de ativos específicos como comportamentos entrópicos (FREIRE, 2015).

\footnotetext{
41 “El 'óptimo de Pareto' (criterio paretiano), según el cual una decisión es óptima cuando alguien puede mejorar su situación sin empeorar la del otro; siendo ésta la mayor concesión de sensibilidad social, que acepta la vertiente moderada del AED (Calabresi)" (VANOSSI, 2008, p. 59).

42 Sobre a funcionalização das estruturas jurídicas, ver Tepedino (2008, p. 400).

43 "A liberdade de contratar é fundamental para aumentar o bem-estar de todos. Essa a função social do contrato, criar bem-estar" (SZTAJN, 2007, p. 47).

44 "Para que o mercado possa promover o fluxo de relações económicas de maneira eficiente, é necessário que as partes, ao se vincularem, tenham acesso às informações necessárias à tomada de decisão, sob pena de desestímulo às contratações, por aumento dos custos a elas relacionados" (FORGIONI, 2005, p. 246).
} 
No âmbito do relativo dolo de oportunismo, por exemplo, tem-se quebra da relação de lealdade entre as partes (e aí tem-se, v.g., forte carga valorativa no paradigma da eticidade) pelo desvio proposital no comportamento padrão a causar prejuízos, e a ruptura do sinalagma pactual. Muitas das vezes, os oportunismos estão conectados ao uso de assimetrias informacionais ligadas à reserva mental, no intuito de inadimplir o negócio entabulado pelas partes, a infringir, assim, o cumprimento pontual do acordo firmado. ${ }^{45}$ Excelente exemplo para enxergar o fenômeno em comento, e a formação de uma consequente hold up negocial, é a Teoria da Agência, ${ }^{46}$ de natureza contratualista relacional, posta, inclusive, como um restatement of the Law of contracts.

Nesse sentido, e.g., na condução de contratos de longa duração, como é o de agência, deve-se observar, sempre, dentre aspectos ligados aos deveres, resultados e prejuízos: a ausência de conflitos de interesses; preservação do sigilo negocial; dever de diligência normal; respeito aos limites negociais traçados (mesmo de preços mínimos e máximos); o repasse transparente e ágil das informações; dever de indenizar; etc. (PRADO FILHO, 2010, p. 202, 215).

Na seara dos ativos específicos, e com enfoque mais pragmático, é fácil constatar, por exemplo, a formação de monopsônios ilegais, ou seja, sem o manto da dominação mercadológica eficiente, mas sim por meio da exploração da posição exclusiva e/ou dominante de mercado, a ensejar a fixação de preços exorbitantes, o controle no fornecimento de eventual matéria-prima, além de outras irregularidades.

A tônica é deveras relevante aos contratos relacionais que envolvem propriedade intelectual, porquanto, muitas das vezes, a AED autorizaria, sobretudo em caso de cobrança de royalties abusivos e/ou em situações de relevante interesse social na defesa de alguns direitos fundamentais, a quebra das patentes de produtos farmacêuticos e de tecnologia disruptiva, a atingir, assim, o sistema de incentivos socioeconômicos (FREIRE, 2015). De aplicação inserta nesse contexto, é importante salientar uma visão de AED para além da própria seara cível-empresarial, como concretizante de direitos fundamentais, vejamos, pois, o seguinte argumento:

O simples fato de a estrutura normativa ter sido delineada juridicamente com o escopo de concretização dos direitos fundamentais não garante que efetivamente ela cumprirá com este papel. A compreensão do Direito distanciado da realidade social, política e econômica não é suficiente para dar conta da complexidade da sociedade contemporânea. É utópico entender que a mera eficácia formal das normas jurídicas será suficiente para garantir que, em todas as hipóteses, a finalidade para a qual tais normas delineadas serão alcançadas (RIBEIRO; CAMPOS, 2012, p. 320).

Se, por um lado, a abertura das patentes funcionaria como veículo assegurador de direitos fundamentais, por outro ângulo desestimularia investimentos em pesquisa e inovação tecnológica. Sob tal perspectiva, é mais atilado defender o licenciamento compulsório, com a fixação de royalties equitativos, solução hábil à geração de mais eficiência socioeconômica.

Sem embargo, o dilema das assimetrias informacionais pode ocorrer com ainda mais complexidade quando se verifica o uso púnico de bundle of sticks e, ainda, por intermédio da formação de carteis embuçados de clusters (aglomerados) empresariais, com o fito de definir o curso das relações mercantis (FREIRE, 2015).

A considerar essa lógica de entropias, as partes negociantes devem conceber instrumentos contratuais sob um desiderato mitigador da álea, ou seja, dos riscos ex ante e ex post, a evitar, ao máximo, a ocorrência de externalidades, bem como a possibilitar a reparação por malefícios, embora já se esteja a despargir, até mesmo, a tese de compensação por externalidade positiva.

\footnotetext{
${ }^{45}$ Interessante caso envolvendo o assunto em tela, assimetria informacional, por exemplo, foi julgado pela CVM nos autos do Processo Administrativo Sancionador CVM no RJ2014/10082 (CVM, 2016).

46 "O emprego do conceito de agency na common law é muito mais amplo do que a relação estrita de distribuição de bens; ainda que nada pareça impedir sua utilização com a finalidade de auxiliar a circulação de bens, a relação formalizada desta maneira virá acrescida de toda a fidúcia própria desta figura" (PRADO FILHO, 2010, p. 202).
} 
É, nessa toada, que se passou a admitir o contrato sob uma perspectiva dinâmica, e não mais estática, a abranger desde as negociações prévias até os efeitos posteriores ao adimplemento, tudo através de uma coordenação positiva e/ou negativa do contrato (TERRA; BANDEIRA, 2015, p. 12).

É exatamente aí que se insere a metodotização dos contratos incompletos: primeiramente em decorrência da exposta visão dinâmica do contrato; segundo, porque é essencial perceber que existem contratos simétricos cujas realizações dependem, necessariamente, de renegociações, com o fito de corrigir a quebra do balanço econômico financeiro; terceiro, pela possibilidade de eventual alteração no comportamento das partes, e, por último, mas não menos importante, em detrimento da incapacidade humana de antever incidentes supervenientes; a falar-se, assim, de limitação da racionalidade.

Essa limitação da racionalidade faz com que surjam os contratos incompletos, pois a mente humana não é capaz de prever todas as possibilidades ex ante, acarretando na necessidade de revisão do contrato ex post. Por essa razão, a Economia dos Custos de Transação é orientada a identificar os distintos mecanismos ex post de solução de conflitos contratuais, relacionando-os ao poder outorgado ao empresário para resolver o conflito (PALHANO, 2016, p. 164).

Em outras palavras, a gestão dos riscos deve ser feita, seja a partir da delimitação ex ante de ameaças contratuais ordinárias, isto é, mediante uma configuração positiva do contrato, no sentido de gerenciar fatos previsíveis e inerentes à atividade, seja, de outra forma, por intermédio de uma prognose de ameaças supervenientes, a configurar, desse modo, um gerenciamento negativo das externalidades. Nessa lógica, compreende-se, em todo caso, o negócio jurídico sob o manto da relatividade de suas cláusulas, a possibilitar, assim, decremento de custos transacionais (TERRA; BANDEIRA, 2015, p. 14).

No tocante à gestão negativa das externalidades ex post, deve-se pontuar que os contratos serão considerados incompletos pela fixação de cláusulas em branco (ou de constante renegociação), a viabilizar a restauração ou a redefinição do equilíbrio contratual galgado na necessidade, como já dito, de manutenção contínua do sinalagma da relação contratual. Sem embargo, tem-se observado a utilização de preceitos negociais a autorizar a inserção de previsões resolutórias expressas e a extinguir a obrigação de forma ipso iure (TERRA; BANDEIRA, 2015, p. 14).

Saliente-se, por fim, que, preferencialmente, a administração dos riscos nos contratos relacionais deve ser feita por intermédio das forças endógenas do mercado ou, ainda, das peculiaridades da atividade. Não obstante, como visto, tanto em Coase (1960, passim) quanto na argumentação de Maria Luiza Pereira de Alencar Mayer Feitosa (2005, p. 75-76), não se dispensa atuação judicial no sentido de preservar a socialidade contratual, a salvaguardar os ditames do desenvolvimento socioeconômico sustentável.

\section{CONCLUSÃO}

As transformações que estão a ocorrer na ciência do Direito têm possibilitado a abertura de diversos campos hermenêuticos com supedâneo neopositivista, ou seja, na percepção de uma carga valorativa principiológica, e outros enfoques, como pilares empreendedores das relações sociais.

Apesar de certa resistência - galgada muito mais na observação dos exageros do que das virtudes dessa fenomenologia de projeção global, de fortíssimo impacto no Ocidente -, verifica-se que o Direito marcha, em compasso, para o reconhecimento de sua integralidade, como explicação a um interpretativismo para além da simples literalidade dos verbetes, diga-se, lexicográficos, ou seja, que se projete para albergar, e.g., economia, finança, política, cultura, meio ambiente e solidariedade, conforme uma acepção democrática e dialógica. Negar tal aspecto, o que seria admissível como incitação à antítese hegeliana, é furtar-se à modernidade líquida que, feliz ou infelizmente, tem emaranhado todas as ações humanas.

É nessa ótica, precisamente, que se insere a aceitação da Análise Econômica do Direito - AED -, considerada a partir da consciência da existência de sistemas herméticos, porém interativos, aptos, conjuntamente, à construção do desenvolvimento humano holístico e sustentável, com norte, principalmente, no sujeito enquanto indivíduo e como componente de uma coletividade autônoma. Nessa razão, fica fácil enxergar o valor do paradigma da socialidade socioeconômica. 
O Direito Civil e o Direito Empresarial, influenciados pelas acepções postas nos argumentos aqui trazidos, sofreram (e têm suportado) renovações em sua matriz dogmática, no sentido de visualizar, dentre outras teorias, a relativização do dirigismo contratual, a funcionalização das estruturas jurídicas, e, até mesmo, o diálogo das fontes entre as ciências jurídica e econômica, daí falar-se em um criticismo jus economicista.

Vê-se, aí, não somente a mutação da significância da propriedade, mas, também, a alteração dos seus propícios conglomerados de ferramentas legais, que lhe emprestam ou, melhor, lhe acrescentam ainda mais importância. Inserto nesse contexto, está o contrato, elemento, pois, crucial às trocas em comunidade, sendo essencial projetá-lo à consubstanciação de mais palpável eficiência, por intermédio de um arranjo de incentivos à diminuição de custos transacionais, a gerar, consequentemente, mais-valia, surplus value.

Deve-se, todavia, registrar que a AED passou a receber mais estímulos a partir das ideias de Ronald Coase, que, em The problem of social cost (1960), ao avaliar externalidades negativas, harmful effects, concluiu acerca da necessidade de soluções negociais endógenas ao próprio mercado, sem, entretanto, desprezar, dada a relevância social de eventual matéria posta em casos concretos, a pertinência do intervencionismo estatal, seja por meio de uma abordagem positiva e/ou normativa. ${ }^{47}$

A partir dessa logicidade, verifica-se a refundamentação das teorias contratuais clássica e neoclássica, passando a se admitir a edificação de uma metodotização de contratos simétricos relacionais (ou de longa duração), nos quais a necessidade de renegociação constante dá-se pela aferição da dinamicidade contratual, sem embargo à análise de riscos negociais, sejam eles detectáveis ex ante e/ou ex post.

Dessa forma, compreende-se a necessidade de apreender o contrato como uma ferramenta não somente jurídica, mas também econômica, pois o desenho de suas diretrizes intrínsecas pode encorajar a distribuição de intitulamentos às partes subscritoras e a toda a sociedade. Galgada nessa inteligência, tem-se utilizado a fixação de cláusulas em branco, bem como de cláusulas resolutórias expressas, aptas à mitigação da álea pactual, a evidenciar-se, entrementes, a incompletude dos instrumentos contratuais, por mais completos que venham a se caracterizar.

Pelo exposto e a retomar as ideias primevas, postas no presente artigo acadêmico, torna-se inegável aceitar uma realidade jus economicista no tocante à Teoria Geral dos Contratos. Dessarte, a formação de sistemas jurídicos mistos, por meio de uma comunicação do common law com o direito europeu continental, passa a ser cada vez mais tangível.

Malgrado as inúmeras críticas direcionadas à AED, fundamentadas notadamente na rejeição do utilitarismo científico espiritual, parece-nos imprudente conceber razões radicais, porquanto a percepção da utilidade não despreza o recrudescimento do indivíduo, muito pelo contrário, inflama a constituição de uma sociedade fomentadora de uma democracia nos termos traçados por Amartya Sen (2009) em Desenvolvimento como Liberdade.

Por fim, a Análise Econômica do Direito, como fora dito, dispensa preconcepções estultificantes, sejam elas fulcradas em ortodoxias liberais ou planificadas, isso porque a AED é vital à tomada de relevantes decisões legislativas, contratuais e/ou judiciais, aqui, acolá e onde mais sejam deliberadas escolhas com repercussões no tecido social.

\section{REFERÊNCIAS}

ALVAREZ, Alejandro Bugallo. Análise econômica do Direito: contribuições e desmistificações. Revista de Direito, Estado e Sociedade, Rio de Janeiro: PUC-Rio, n. 29, out. 2006.

ARAÚJO, Fernando. Teoria econômica do contrato. Coimbra: Almedina, 2007.

ARAÚJO, Nadia de. Direito Internacional Privado: teoria e prática brasileira. 5. ed. Rio de Janeiro: Renovar, 2011 ASSIS NETO, Sebastião de; DE JESUS, Marcelo; DE MELO, Maria Izabel. Manual de Direito Civil. Salvador: Juspodivm, 2013.

AZOIA, Viviane Taís; RIBEIRO, Marcia Carla Pereira. A função social dos contratos e as externalidades: uma análise econômica. Revista do Mestrado em Direito, Brasília: Universidade de Brasília, n. 2. dez. 2016. Disponível em: https://portalrevistas.ucb.br/ index.php/rvmd/article/viewFile/7595/4774. Acesso em: 23 maio 2018.

${ }^{47}$ Cf. Ribeiro; Campos, 2012, p. 314. 
BATTESINI, Eugênio. Curso de Direito e Economia: análise econômica do direito e o direito da regulação econômica. Porto Alegre. 2015. Disponível em: https://www.youtube.com/watch?v=g0T-tXv3G1l. Acesso em: 23 maio 2018.

BAUMAN, Zygmunt. Modernidade líquida. Tradução: Plínio Dentzien. Rio de Janeiro: Zahar, 2001.

BERTOLDI, Marcelo M.; RIBEIRO, Marcia Carla Pereira. Curso avançado de Direito Comercial. 4. ed. São Paulo: Revista dos Tribunais, 2008.

BIAZUS, Joana Tonetti. A posse-trabalho, prevista no art. 1.228, §§4ำ e 5으, do código civil, como forma de aquisição da propriedade através da usucapião especial coletivo. Revista VLex, n. 3. [S.I.]: Editora VLex, 2008.

BRASIL. Lei $n$ o 10.406, de 10 de jan. de 2002. Disponível em: http://www.planalto.gov.br/ccivil_03/Leis/2002/l10406.htm. Acesso em: 30 maio 2018.

CASTILHO, José Roberto Fernandes. Disciplina urbanística da propriedade - o lote e seu destino. São Paulo: Editora Pillares, 2010.

CVM. Comissão de Valores Mobiliários. Processo administrativo sancionador sob no RJ2014/10082. 2016. Disponível em: http://www.cvm.gov.br/export/sites/cvm/sancionadores/sancionador/anexos/2017/RJ201410082_Contax_Participacoes.pdf. Acesso em: 23 out. 2018.

COASE, Ronald Harry. The problem of social cost. The Jornal of Law and Economics, [S.I.], v. III, p. 1-44, Oct. 1960. Disponível em: https://www.law.uchicago.edu/files/file/coase-problem.pdf. Acesso em: 28 maio 2018.

DIAS, Gustavo Neto de Carvalho. O contrato-tipo e a aplicação do CDC aos contratos empresariais. Revista de Direito Mercantil, Industrial, Econômico e Financeiro, São Paulo: Malheiros Editores, n. 148, out. 2009.

ENCYCLOPAEDIA BRITANNICA. Apresenta informações gerais. Disponível em: https://www.britannica.com/biography/Ronald-Coase. Acesso em: 16 maio 2018.

FAGANELLO, Tiago. Contratos empresariais de longa duração e incompletude contratual. 2017. Dissertação (Mestrado em Fundamentos Constitucionais do Direito Público e do Direito Privado) - Faculdade de Direito, Pontifícia Universidade Católica do Rio Grande do Sul, Porto Alegre, 2017. Disponível em: http://repositorio.pucrs.br/dspace/bitstream/10923/10861/1/ 000485418-Texto\%2bParc

ial-0.pdf. Acesso em: 30 maio 2018.

FEITOSA, Maria Luiza Pereira de Alencar Mayer. O contrato como regulador e como produtor de riscos. 2005. Disponível em: http://www.periodicos.ufpb.br/ojs/index.php/primafacie/article/view/4507/3392. Acesso em: 23 maio 2018.

FEITOSA, Maria Luiza Pereira de Alencar Mayer. As relações multiformes entre contrato e risco. 2005. Revista de Direito Mercantil, Industrial, Econômico e Financeiro, São Paulo: Malheiros Editores, n. 139, jul. 2005.

FERNANDES, Bernardo Gonçalves. Curso de Direito Constitucional. 6. ed. Salvador: Juspodivm, 2014.

FORGIONI, Paula A. Análise econômica do Direito (AED): paranóia ou mistificação? Revista de Direito Mercantil, Industrial, Econômico e Financeiro., São Paulo: Malheiros Editores, n. 139, jan. 2005.

FREIRE, Maria Paula Reis Vaz. Curso de Direito e Economia: análise econômica do direito e o direito da regulação econômica. Porto Alegre. 2015. Disponível em: https://www.youtube.com/watch?v=QvbR0XPIJe8\&t=19s. Acesso em: 16 maio 2018.

GARCIA, Leonardo de Medeiros. Direito do consumidor: código comentado e jurisprudência. 9. ed. Salvador: Juspodivm, 2013. GAROUPA, Nuno. Combinar a economia e o Direito: a análise econômica do Direito. Disponível em: https://www.passeidireto. com/arquivo/2646313/nuno-garoupa---combinar-a-economia-e-o-direito. Acesso em: 30 maio 2018.

GICO JUNIOR, Ivo T. Economic Analysis of Law Review: metodologia e epistemologia da análise econômica do Direito. Distrito Federal: Grupo de Pesquisa em Direito e Economia, 2010. Disponível em: Acesso em: 10 jun. 2018.

HENRIQUES, Antônio; MEDEIROS, João Bosco. Monografia no curso de Direito. Trabalho de conclusão de curso; metodologia e técnicas de pesquisa - da escolha do assunto à apresentação gráfica. 3. ed. São Paulo: Atlas, 2003.

LOYOLA, Paulo Ricardo Gontijo. Valor e mais-valia: examinando a atualidade do pensamento econômico de Marx. Disponível em: http://repositorio.ufc.br/bitstream/riufc/3519/1/2009_Art_PRGLoyola.pdf. Acesso em: 16 maio 2018.

LYBRARY ECONOMICS LIBERTY. Apresenta informações gerais. Disponível em: http://www.econlib.org/library/Enc1/bios/Coase.html. Acesso em: 16 maio 2018.

MARCHESAN, Ana Maria; STEIGLEDER, Annelise; CAPPELLI, Sílvia. Direito ambiental. 7. ed. Porto Alegre: Verbo Jurídico, 2013. MENEZES, Renata; MAGALHÃES, Bianca; MAGALHÃES, Sandro. Aspectos jurídicos econômicos apresentados no filme "Fome de Poder": com base na Teoria Social dos Contratos e na Análise Econômica do Direito. Revista Jurídica Luso Brasileira, 2018. Disponível em: https://www.cidp.pt/publicacoes/revistas/rjlb/2018/5/2018_05_1429_1452.pdf. Acesso em: 14 set. 2018.

OLIVEIRA, Rafael Carvalho Rezende. Curso de Direito Administrativo. 2. ed. São Paulo: Método, 2014.

PALHANO, Ana Paula Marangoni. Compra e venda de soja na indústria de óleo e farelo à luz da Teoria da Economia do Custo de Transação. Rio de Janeiro: FGV; Direito Rio, nov. 2016. (Coleção jovem jurista, n. 2016 ). 
PENTEADO, Luciano de Camargo. Figuras parcelares da boa-fé objetiva e venire contra factum proprium. 2006. Disponível em: http://www.cantareira.br/thesis2/ed_8/3_luciano.pdf. Acesso em: 17 set. 2018.

PIMENTA, Eduardo Goulart. Análise econômica do regime jurídico-constitucional da empresa no Direito brasileiro. Revista Novos Estudos Jurídicos, Itajaí: Univali, n. 21-1, jan. 2015.

PORTELA, Paulo Henrique Gonçalves. Direito Internacional Público e Privado. 7. ed. Salvador: Juspodivm, 2015.

PORTO, Antônio José Maristrello. Análise Econômica do Direito (AED). 2013. Disponível em: http://direitorio.fgv.br/sites/direitorio.fgv.br/files/u100/analise_economica_do_direito_20132.pdf. Acesso em: 16 maio 2018.

PRADO FILHO, José Inácio Ferraz de Almeida. Duas reflexões sobre o contrato de agência: identidade/distinções pertinentes e critérios próprios na aplicação da regra da razão antitruste. Revista de Direito Mercantil, Industrial, Econômico e Financeiro. São Paulo: Malheiros Editores, n. 153-154, jan. 2010.

REALE, Miguel. Lições preliminares de Direito. 27. ed. São Paulo: Saraiva, 2007.

REALE, Miguel. Visão geral do Projeto de Código Civil. 1998. Disponível em: http://www.ufrgs.br/ppgd/doutrina/reale1.htm. Acesso em: 16 maio 2018.

REALE, Miguel. Visão geral do Novo Código Civil. 2002. Disponível em: https://jus.com.br/artigos/2718/visao-geral-do-novo-codigo-civil/1. Acesso em: 16 maio 2018.

RIBEIRO, Márcia Carla Pereira; CAMPOS, Diego Caetano da Silva. Análise econômica do Direito e a concretização dos direitos fundamentais. Revista de Direitos Fundamentais \& Democracia, . [S.I.]: Unibrasil, n. 11, jan. 2012.

SEN, Amartya. Desenvolvimento como liberdade. São Paulo: Companhia das Letras. 2009.

SCRAMIN NETO, Geraldo; FERREIRA, Jussara. Revisão contratual e função social. 2013. Revista de Ciências Jurídicas e Sociais da Unipar, Umuarama: Unipar, n. 16-1, jan. 2013.

SHUNCK, Giuliana Bonanno. Contratos de longo prazo e dever de cooperação. 2013. Tese (Doutorado em Direito Civil) - Faculdade de Direito, Universidade de São Paulo, São Paulo, 2013. Disponível em: http://www.teses.usp.br/teses/disponiveis/2/2131/tde-28032014-144357/pt-br.php. Acesso em: 30 maio 2018.

SILVA FILHO, Osny da. Entre mercado e hierarquia: repercussões da desverticalização na disciplina dos contratos empresariais. 2014. Revista de Direito Mercantil, Industrial, Econômico e Financeiro, São Paulo: Malheiros Editores, n. 163 , set. 2014.

SZTAJN, Rachel. Função social do contrato e direito de empresa. 2007. Revista de Direito Mercantil, Industrial, Econômico e Financeiro, São Paulo: Malheiros Editores, n. 139, jul. 2007.

TARTUCE, Flávio. A desapropriação judicial privada por posse-trabalho e o caso da Favela Pullman. Semelhanças e diferenças. Concretizando a função social da propriedade e da posse. Revista de Direito Privado, São Paulo: Revista dos Tribunais, v. 54, jun. 2013.

TEIXEIRA, Igor Veiga Carvalho Pinto. A diferença entre os contratos de adesão e os contratos tipo. 2011. Disponível em: http:// www.conteudojuridico.com.br/artigo,as-diferencas-entre-os-contratos-de-adesao-e-os-contratos-tipo,33583.html. Acesso em: 19 set. 2018.

TEPEDINO, Gustavo. Notas sobre a função social dos contratos. 2008. Disponível em: http://www.tepedino.adv.br/wpp/wpcontent/uploads/2017/07/Notas_Sobre_Funcao_Social_Contratos_fls_395-405.pdf. Acesso em: 23 out. 2018.

TERRA, Aline de Miranda Valverde; BANDEIRA, Paula Greco. A cláusula resolutiva expressa e o contrato incompleto como instrumentos de gestão de risco nos contratos. 2015. Disponível em: https://rbdcivil.ibdcivil.org.br/rbdc/article/view/80/183. Acesso em: 23 out. 2018.

VANOSSI, Jorge Reinaldo. La aplicación constitucional del "el análises económico del Derecho (AED)": ¿nada menos y nada más que un "enfoque"? 2008. Disponible em: https://www.ancmyp.org.ar/user/files/02Vanossi.pdf. Acceso en: 28 maio 2018.

VELOSO, Sílvia Mechelany. Análise econômica da função social do contrato - Art. 421 do Código Civil. Direito Privado, São Paulo, v. 54, abr./jun. 2013.

VENOSA, Sílvio de Salvo. Direito Civil: Teoria geral das obrigações e teoria geral dos contratos. 6. ed. São Paulo: Atlas, 2006.

ZANELLA, C. et al. Conhecendo o campo da economia dos custos de transação: uma análise epistemológica a partir dos trabaIhos de Oliver Williamson. 2015. Revista de Ciência da Administração, Florianópolis: Universidade Federal de Santa Catarina, $\mathrm{n}$. 17-42, ago. 2015. 